\title{
IMPLEMENTASI ALGORITMA APRIORI PADA SISTEM PERSEDIAAN BARANG
}

\author{
Elfrida L Hutahaean ${ }^{1}$, M. Safii ${ }^{2}$, Bahrudi E Damanik ${ }^{3}$ \\ 1,2,3Program Studi Teknik Informatika STIKOM TUNAS BANGSA Pematangsiantar \\ Email: ${ }^{1}$ lucyana.hutahaean@gmail.com, ${ }^{2}$ m.safii@amiktunasbangsa.ac.id, ${ }^{3}$ bahrudiefendi@gmail.com
}

(Naskah masuk: 7 September 2020, diterima untuk diterbitkan: 27 Oktober 2020)

\begin{abstract}
Abstrak
Persediaan merupakan salah satu faktor penentu kelancaran dalam penjualan, maka dari itu persediaan seharusnya dikelola dengan baik. Jika persediaan produk kurang, pelanggan akan kecewa dan jika persediaan berlebih, akan menimbulkan penumpukan barang dan terjadi kerugian. Perkembangan teknologi saat ini dapat dimanfaatkan untuk melakukan pengolahan data-data transaksi yang ada agar persediaan barang dimasa yang akan datang dapat termanajemen dengan baik. Data Mining merupakan proses menemukan suatu pola atau informasi yang menarik dalam suatu data dengan metode tertentu. Rapidminer adalah perangkat lunak yang digunakan untuk mengolah data-data sehingga data bisa menjadi informasi. Algoritma Apriori yaitu algoritma yang digunakan untuk menemukan pola frekuensi tertinggi dan menemukan aturan asosiatif kombinasi antara itemset dengan cara pembentukan kandidat-kandidat yang akan diseleksi melalui minimum support dan confidence dan penemuan pola kombinasi antar itemset digunakan aturan asosiasi. Pola kombinasi ini yang nanti nya akan memberikan informasi barang apa saja yang harus memiliki persediaan lebih banyak dan persediaan barang yang lebih sedikit sehingga lebih efektif lagi dalam meminimalisir penumpukan barang dan kerugian serta pelayanan pelanggan dapat berjalan dengan baik dimasa yang akan datang.
\end{abstract}

Kata kunci: persediaan barang, data mining, algoritma apriori

\section{IMPLEMENTATION OF APRIORI ALGORITHM ON GOODS SUPPLY SYSTEM}

\begin{abstract}
Inventory is one of the determining factors of smooth sales, therefore inventory should be managed properly. If the product inventory is lacking, customers will be disappointed and if the inventory is oversupd, it will cause a buildup of goods and there will be losses. The development of current technology can be utilized to process existing transaction data so that the inventory of goods in the future can be well-equipped. Data Mining is the process of finding a pattern or information that is interesting in a data with a specific method. Rapidminer is a software that is used to process data so that it can become information. The Apriori algorithm is an algorithm used to find the highest frequency patterns and find associative rules of combination between itemsets and the way candidates are selected through minimum support and confidence and the discovery of combination patterns between itemsets used association rules. This combination pattern will provide information on what goods should have more inventory and fewer supplies so that they are more effective in minimizing the build-up of goods and losses and customer service can run well in the future.
\end{abstract}

Keywords: inventory, data mining, apriori algorithm

\section{PENDAHULUAN}

Perkembangan teknologi informasi disaat sekarang ini sangat pesat dan dapat dimanfaatkan untuk memudahkan semua urusan [1]. Salah satu kecanggihan teknologi informasi dapat dilihat dari penggunaan komputer yang sangat luas diberbagai bidang terutama dalam bisnis [2]. Perkembangan teknologi tersebut juga mempunyai dampak terhadap dunia bisnis yaitu peningkatan efektifitas, efisiensi kerja serta peningkatan untuk memenuhi permintaan konsumen. Hal ini memicu pelaku bisnis agar dapat memanajemen persediaan produk penjualan mereka sehingga bisa bertahan dalam dunia bisnis.

UD. Ht. Haean adalah salah satu usaha dagang atau grosir yang berlokasi di Jalan Parapat KM 4,5. Produk yang dijual adalah barang-barang keperluan dapur, barang-barang keperluan sehari-hari, dan lain-lain. Saat ini UD. Ht. Haean masih melakukan pemenuhan persediaan produk dan pencatatan transaksi masih dilakukan menggunakan kertas.

Permasalahan dalam penelitian ini adalah UD. Ht. Haean masih melakukan perhitungan dengan menggunakan kertas dan menghitung langsung ke 
gudang produk yang persediaannya masih cukup ataupun kurang membuat proses persediaan barang tidak efektif dan data persediaan produk penjualan belum tersedia dalam laporan harian perusahaan, sehingga pemilik perusahaan tidak dapat dengan cepat melakukan pengisian produk kembali. Persediaan sangat berperan penting maka dari itu harus dikelola sangat dengan baik karena persediaan sangat berpengaruh pada pelayanan pelanggan dan pendapatan suatu bisnis.

Data mining yaitu suatu proses pendukung untuk mengambil keputusan dimana kita mencari informasi dalam suatu data [3]. Dengan data mining dapat memanfaatkan data-data lampau untuk mencari solusi pada data-data yang akan dating setelahnya [4]. Data mining memberikan solusi kepada pemilik perusahaan dalam mengambil keputusan guna meningkatkan bisnis. Dengan algoritma apriori dapat merekomendasikan hasil yang di harapkan dapat membantu dalam mendukung keputusan persediaan barang [5].

Penelitian sebelumnya mengatakan algoritma apriori dapat membantu untuk mengetahui nama item barang dengan penjualan terbanyak. Hasil yang didapat melalui proses algoritma apriori berupa kombinasi item atau rules dengan nilai support dan confidence. Dengan diketahuinya nama barang paling banyak terjual maka dapat mengantisipasi persediaan barang [6].

Penelitian lainnya membahas tentang penerapan Data Mining algoritma Apriori dalam memprediksi stock barang penjualan sepatu digunakan dengan tujuan membantu suatu perusahaan dalam memprediksi jenis barang yang laku dan tidak laku pada suatu penjualan. Hasil yang didapat adalah perusahaan bisa lebih mudah dalam menyediakan produk yang lebih dibutuhkan pelanggan berdasarkan stok sepatu converse yang ada. Sehingga penjualan sepatu meningkat dan memberikan keuntungan bagi perusahaan karena pelanggan merasa puas dengan barang yang ditawarkan oleh perusahaan [7]

Penelitian ini bertujuan untuk mengolah data transaksi yaitu mencari pola kombinasi agar dapat menyelesaikan masalah persediaan barang untuk bulan selanjutnya pada UD. Ht. Haean.
Data mining adalah teknik yang cukup mudah dan cepat untuk menemukan pola dan/atau relasi antar data, secara otomatis. Dengan menggabungkan empat disiplin ilmu komputer syaitu definisi diatas, pengetahuan bisa ditemukan dalam lima proses berurutan: seleksi, pemprosesan, transformasi, data mining, dan interprestasi/evaluasi [8].

Algoritma Apriori yaitu langkah-langkah dalam menemukan frequent-itemset [9] dari kandidat-kandidat itemset yang memenuhi nilai minimum yang telah ditentukan. Prinsip dari algoritma Apriori bila itemset digolongkan sebagai frequent-itemset yang memiliki support lebih dari yang ditetapkan, maka semua subsetnya tergolong frequent-itemset, dan juga sebaliknya[10].

frequent-itemset ini yang akan di jadikan kombinasi untuk pencarian aturan asosiasi dengan memenuhi minimum confidence [11].

Tahap yang ada pada metode ini yaitu

(a) Tahap pengumpulan data,

(b) Tahap Transformasi Data, dan

(c) Tahap analisis

A. Tahap Pengumpulan Data

Pengumpulan data dengan cara mendapatkan catatan tentang persediaan, transaksi maupun catatan lainnya yang menyangkut tentang persediaan produk pada UD. Ht. Haean. Data yang diambil yaitu data pada bulan februari dan terdapat 632 transaksi.

B. Tahap Transformasi Data

Ditahap ini data-data transaksi akan diubah menjadi bentuk tabel tabulasi. Tujuan data di ubah menjadi tabel tabulasi agar data dapat dipakai untuk tahap selanjutnya.

C. Tahap Analisis

Selanjutnya ditahap ini data akan dianalisis menggunakan algoritma apriori dan aplikasi Rapidminer untuk mencari pola-pola hubungan yang ada pada itemset.

\section{HASIL DAN PEMBAHASAN}

Sebagaimana yang telah dijelaskan pada metode penelitian tahapan awal penelitian ini yaitu tahap pengumpulan data. Berikut adalah data dari Ud. Ht. Haean dari bulan februari dapat dilihat pada dilihat pada Tabel 1 berikut

\section{METODE PENELITIAN}

Tabel 1. Data Transaksi Ud. Ht. Haean

\begin{tabular}{cc}
\multicolumn{2}{c}{ Tabel 1. Data Transaksi Ud. Ht. Haean } \\
\hline Itemset & Total Transaksi \\
\hline Gula & 184 \\
Minyak Makan & 155 \\
Sabun Mandi & 18 \\
Sabun Cuci & 27 \\
Kelapa & 38 \\
Tepung & 51 \\
Shampoo & 30 \\
Susu & 62 \\
Penyedap Rasa & 25
\end{tabular}




\begin{tabular}{cc} 
Saos & 34 \\
Rokok & 163 \\
Deterjen & 43 \\
Kopi & 67 \\
Garam & 61 \\
Mie Instant & 59 \\
\hline Beras & 84 \\
Bensin & 45 \\
Plastik & 43 \\
Telur & 106 \\
Roti & 44 \\
Bubuk Teh & 25 \\
Gas & 23 \\
Mancis & 12 \\
Pelembut Pakaian & 6 \\
Popok & 13 \\
Air Mineral & 16 \\
Kacang & 12 \\
Odol & 25 \\
Gula Merah & 12 \\
\hline
\end{tabular}

Selanjutnya data-data transaksi tersebut di ubah menjadi tabel tabulasi agar mudah untuk melakukan analisa di metode dan aplikasi Rapidminer

\subsection{Pembentukan 1 Itemset}

Pembentukan $\mathrm{C} 1$ atau disebut juga 1 Itemset dari data transaksi dengan total transaksi 632 akan dihitung supportnya dengan minimal support yang ditentukan adalah 5\% dihitung menggunakan rumus:

$$
\operatorname{Support}(\mathrm{A})=\frac{\mathrm{Jlh} \text { Transaksi Mengandung A }}{\text { Total Transaksi }} \times 100 \% \text { (1) }
$$

Tabel 2. Kandidat 1 itemset

\begin{tabular}{|c|c|c|}
\hline Itemset & \multicolumn{2}{|l|}{ Support } \\
\hline Gula & $184 / 632 \times 100 \%$ & $29,11 \%$ \\
\hline Minyak Makan & $155 / 632 \times 100 \%$ & $24,52 \%$ \\
\hline Sabun Mandi & $25 / 632 \times 100 \%$ & $3,95 \%$ \\
\hline Sabun Cuci & $27 / 632 \times 100 \%$ & $4,27 \%$ \\
\hline Kelapa & $38 / 632 \times 100 \%$ & $6,01 \%$ \\
\hline Tepung & $51 / 632 \times 100 \%$ & $8,07 \%$ \\
\hline Shampoo & $29 / 632 \times 100 \%$ & $4,59 \%$ \\
\hline Susu & $62 / 632 \times 100 \%$ & $9,81 \%$ \\
\hline Penyedap Rasa & $25 / 632 \times 100 \%$ & $3,95 \%$ \\
\hline Saos & $34 / 632 \times 100 \%$ & $5,38 \%$ \\
\hline Rokok & $163 / 632 \times 100 \%$ & $25,79 \%$ \\
\hline Deterjen & $43 / 632 \times 100 \%$ & $6,80 \%$ \\
\hline Kopi & $67 / 632 \times 100 \%$ & $10,60 \%$ \\
\hline Garam & $61 / 632 \times 100 \%$ & $9,65 \%$ \\
\hline Mie Instant & $59 / 632 \times 100 \%$ & $9,33 \%$ \\
\hline Beras & $84 / 632 \times 100 \%$ & $13,29 \%$ \\
\hline Bensin & $45 / 632 \times 100 \%$ & $7,12 \%$ \\
\hline
\end{tabular}

\begin{tabular}{lll} 
Plastik & $43 / 632 \times 100 \%$ & $6,80 \%$ \\
Telur & $106 / 632 \times 100 \%$ & $16,77 \%$ \\
\multicolumn{1}{c}{ Roti } & $44 / 632 \times 100 \%$ & $6,96 \%$ \\
Bubuk Teh & $25 / 632 \times 100 \%$ & $3,95 \%$ \\
\hline Gas & $23 / 632 \times 100 \%$ & $3,64 \%$ \\
Mancis & $12 / 632 \times 100 \%$ & $1,90 \%$ \\
Pelembut & $6 / 632 \times 100 \%$ & $0,95 \%$ \\
Pakaian & $13 / 632 \times 100 \%$ & $2,05 \%$ \\
Popok & $16 / 632 \times 100 \%$ & $2,53 \%$ \\
Air Mineral & $12 / 632 \times 100 \%$ & $1,90 \%$ \\
Kacang & $25 / 632 \times 100 \%$ & $3,95 \%$ \\
Odol & $12 / 632 \times 100 \%$ & $1,90 \%$ \\
Gula Merah & & \\
\hline
\end{tabular}

Minimum Support yang telah ditentukan oleh penulis adalah 5\%, jadi itemset yang kurang dari 5\% akan dihilangkan sehingga menghasilkan 1 Itemset yang sudah memenuhi minimum support pada Tabel 3berikut:

Tabel 3.Hasil 1 itemset

\begin{tabular}{cc}
\hline Itemset & Support \\
\hline Gula & $29,11 \%$ \\
Minyak Makan & $24,52 \%$ \\
Kelapa & $6,01 \%$ \\
Tepung & $8,07 \%$ \\
Susu & $9,81 \%$ \\
Saos & $5,38 \%$ \\
Rokok & $25,79 \%$ \\
Deterjen & $6,80 \%$ \\
Kopi & $10,60 \%$ \\
Garam & $9,65 \%$ \\
Mie Instant & $9,33 \%$ \\
Beras & $13,29 \%$ \\
Bensin & $7,12 \%$
\end{tabular}




\begin{tabular}{cc} 
Plastik & $6,80 \%$ \\
Telur & $16,77 \%$ \\
Roti & $6,96 \%$ \\
\hline
\end{tabular}

\subsection{Pembentukan 2 Itemset}

Dilakukan dengan cara proses cross item pada 1 Itemset yang telah dicari dan menghitung supportnya dengan rumus :

$\operatorname{Support}(\mathrm{A}, \mathrm{B})=\frac{\mathrm{Jlh} \text { Transaksi Mengandung A,B }}{\text { Total Transaksi }} \times 100 \%(2)$

Tabel 4. Kandidat 2 itemset

\begin{tabular}{|c|c|c|c|c|c|}
\hline \multirow{2}{*}{$\frac{\text { Itemset }}{\text { Gula, Minyak Makan }}$} & \multicolumn{2}{|c|}{ Support } & \multirow{2}{*}{$\frac{\text { Itemset }}{\text { Minyak Makan, Kelapa }}$} & \multicolumn{2}{|c|}{ Support } \\
\hline & $35 / 632 \times 100 \%$ & $5,54 \%$ & & $10 / 632 \times 100 \%$ & $1,58 \%$ \\
\hline Gula, Kelapa & $9 / 632 \times 100 \%$ & $1,42 \%$ & Minyak Makan, Tepung & $39 / 632 \times 100 \%$ & $6,17 \%$ \\
\hline Gula, Susu & $24 / 632 \times 100 \%$ & $3,80 \%$ & Minyak Makan, Susu & $6 / 632 \times 100 \%$ & $0,95 \%$ \\
\hline Gula, Saos & $1 / 632 \times 100 \%$ & $0,16 \%$ & Minyak Makan, Saos & $24 / 632 \times 100 \%$ & $3,80 \%$ \\
\hline Gula, Rokok & $32 / 632 \times 100 \%$ & $5,06 \%$ & Minyak Makan, Rokok & $9 / 632 \times 100 \%$ & $1,42 \%$ \\
\hline Gula, Deterjen & $12 / 632 \times 100 \%$ & $1,90 \%$ & Minyak Makan, Deterjen & $9 / 632 \times 100 \%$ & $1,42 \%$ \\
\hline Gula, Kopi & $28 / 632 \times 100 \%$ & $4,43 \%$ & Minyak Makan, Kopi & $5 / 632 \times 100 \%$ & $0,79 \%$ \\
\hline Gula, Garam & $12 / 632 \times 100 \%$ & $1,90 \%$ & Minyak Makan, Garam & $36 / 632 \times 100 \%$ & $5,70 \%$ \\
\hline Gula, Mie Instant & $11 / 632 \times 100 \%$ & $1,74 \%$ & $\begin{array}{c}\text { Minyak Makan, Mie } \\
\text { Instant }\end{array}$ & $10 / 632 \times 100 \%$ & $1,58 \%$ \\
\hline Gula, Beras & $27 / 632 \times 100 \%$ & $4,27 \%$ & Minyak Makan, Beras & $12 / 632 \times 100 \%$ & $1,90 \%$ \\
\hline Gula, Bensin & $4 / 632 \times 100 \%$ & $0,63 \%$ & Minyak Makan, Bensin & $2 / 632 \times 100 \%$ & $0,32 \%$ \\
\hline Gula, Plastik & $2 / 632 \times 100 \%$ & $0,32 \%$ & Minyak Makan, Plastik & $34 / 632 \times 100 \%$ & $5,38 \%$ \\
\hline Gula, Telur & $28 / 632 \times 100 \%$ & $4,43 \%$ & Minyak Makan, Telur & $19 / 632 \times 100 \%$ & $3 \%$ \\
\hline Gula, Roti & $11 / 632 \times 100 \%$ & $1,74 \%$ & Minyak Makan, Roti & $4 / 632 \times 100 \%$ & $0,63 \%$ \\
\hline Kelapa, Tepung & $1 / 632 \times 100 \%$ & $0,16 \%$ & Tepung, Susu & $5 / 632 \times 100 \%$ & $0,79 \%$ \\
\hline Kelapa, Susu & $3 / 632 \times 100 \%$ & $0,47 \%$ & Tepung, Saos & $22 / 632 \times 100 \%$ & $3,48 \%$ \\
\hline Kelapa, Saos & $1 / 632 \times 100 \%$ & $0,16 \%$ & Tepung, Rokok & $1 / 632 \times 100 \%$ & $0,16 \%$ \\
\hline Kelapa, Rokok & $1 / 632 \times 100 \%$ & $0,17 \%$ & Tepung, Garam & $18 / 632 \times 100 \%$ & $2,85 \%$ \\
\hline Kelapa, Garam & $5 / 632 \times 100 \%$ & $0,79 \%$ & Tepung, Plastik & $34 / 632 \times 100 \%$ & $5,38 \%$ \\
\hline Kelapa, Mie Instant & $1 / 632 \times 100 \%$ & $0,16 \%$ & Tepung, Telur & $2 / 632 \times 100 \%$ & $0,32 \%$ \\
\hline Kelapa, Beras & $1 / 632 \times 100 \%$ & $0,16 \%$ & Tepung, Roti & $1 / 632 \times 100 \%$ & $0,16 \%$ \\
\hline Kelapa, Bensin & $1 / 632 \times 100 \%$ & $0,16 \%$ & Saos, Deterjen & $1 / 632 \times 100 \%$ & $0,16 \%$ \\
\hline Kelapa, Telur & $5 / 632 \times 100 \%$ & $0,79 \%$ & Saos, Garam & $11 / 632 \times 100 \%$ & $1,74 \%$ \\
\hline Kelapa, Roti & $1 / 632 \times 100 \%$ & $0,16 \%$ & Saos, Mie Instant & $5 / 632 \times 100 \%$ & $0,79 \%$ \\
\hline Susu, Deterjen & $4 / 632 \times 100 \%$ & $0,63 \%$ & Saos, Beras & $1 / 632 \times 100 \%$ & $0,16 \%$ \\
\hline Susu, Kopi & $10 / 632 \times 100 \%$ & $1,58 \%$ & Saos, Plastik & $23 / 632 \times 100 \%$ & $3,64 \%$ \\
\hline Susu, Garam & $1 / 632 \times 100 \%$ & $0,16 \%$ & Saos, Telur & $6 / 632 \times 100 \%$ & $0,95 \%$ \\
\hline Susu, Mie Instant & $3 / 632 \times 100 \%$ & $0,47 \%$ & Deterjen, Mie Instant & $2 / 632 \times 100 \%$ & $0,32 \%$ \\
\hline Susu, Beras & $6 / 632 \times 100 \%$ & $0,95 \%$ & Deterjen, Beras & $5 / 632 \times 100 \%$ & $0,79 \%$ \\
\hline Susu, Telur & $13 / 632 \times 100 \%$ & $2,06 \%$ & Deterjen, Bensin & $2 / 632 \times 100 \%$ & $0,32 \%$ \\
\hline Susu, Roti & $7 / 632 \times 100 \%$ & $1,11 \%$ & Deterjen, Telur & $5 / 632 \times 100 \%$ & $0,79 \%$ \\
\hline Rokok, Kopi & $31 / 632 \times 100 \%$ & $4,90 \%$ & Deterjen, Roti & $1 / 632 \times 100 \%$ & $0,16 \%$ \\
\hline Rokok, Garam & $7 / 632 \times 100 \%$ & $1,11 \%$ & Garam, Beras & $2 / 632 \times 100 \%$ & $0,32 \%$ \\
\hline Rokok, Mie Instant & $5 / 632 \times 100 \%$ & $0,79 \%$ & Garam, Plastik & $17 / 632 \times 100 \%$ & $2,69 \%$ \\
\hline Rokok, Beras & $12 / 632 \times 100 \%$ & $1,90 \%$ & Garam, Telur & $9 / 632 \times 100 \%$ & $1,42 \%$ \\
\hline
\end{tabular}




\begin{tabular}{cccccc} 
Rokok, Bensin & $24 / 632 \times 100 \%$ & $3,80 \%$ & Garam, Roti & $1 / 632 \times 100 \%$ & $0,16 \%$ \\
Rokok, Plastik & $2 / 632 \times 100 \%$ & $0,32 \%$ & Beras, Telur & $11 / 632 \times 100 \%$ & $1,74 \%$ \\
Rokok, Telur & $9 / 632 \times 100 \%$ & $1,42 \%$ & Beras, Roti & $3 / 632 \times 100 \%$ & $0,47 \%$ \\
Rokok, Roti & $5 / 632 \times 100 \%$ & $0,79 \%$ & Mie Instant, Bensin & $1 / 632 \times 100 \%$ & $0,16 \%$ \\
\hline Kopi, Mie Instant & $2 / 632 \times 100 \%$ & $0,32 \%$ & Mie Instant, Plastik & $1 / 632 \times 100 \%$ & $0,16 \%$ \\
Kopi, Beras & $3 / 632 \times 100 \%$ & $0,47 \%$ & Mie Instant, Telur & $24 / 632 \times 100 \%$ & $3,80 \%$ \\
Kopi, Bensin & $1 / 632 \times 100 \%$ & $0,16 \%$ & Mie Instant, Roti & $4 / 632 \times 100 \%$ & $0,63 \%$ \\
Kopi, Plastik & $2 / 632 \times 100 \%$ & $0,32 \%$ & Kopi, Roti & $6 / 632 \times 100 \%$ & $0,95 \%$ \\
Kopi, Telur & $6 / 632 \times 100 \%$ & $0,95 \%$ & Bensin, Telur & $1 / 632 \times 100 \%$ & $0,16 \%$ \\
\cline { 5 - 6 } Bensin, Roti & $2 / 632 \times 100 \%$ & $0,32 \%$ & & &
\end{tabular}

Kandidat 2 Itemset diatas yang tidak memenuhi minimum support akan dihilangkan dan yang memenuhi minimum support akan digunakan pembentukan itemset berikutnya. Kombinasi 2 Itemset yang didapat dapat dilihat pada tabel 5 berikut:

\begin{tabular}{cc} 
Tabel 5. Hasil kombinasi 2 itemset \\
\hline Itemset & Support \\
\hline Gula, Minyak Makan & $5,53 \%$ \\
Gula, Rokok & $5,06 \%$ \\
Minyak Makan, Tepung & $6,17 \%$ \\
Minyak Makan, Garam & $5,69 \%$ \\
Minyak Makan, Plastik & $5,37 \%$ \\
Tepung, Plastik & $5,54 \%$ \\
\hline
\end{tabular}

\subsection{Pembentukan 3 Itemset}

Pada pembentukan 3 itemset, lakukan kembali cross item pada kombinasi 2 Itemset untuk dapat membentuk kandidat 3 itemset. Berikut kandidat 3 itemset yang didapat.

Support $(\mathrm{A}, \mathrm{B}, \mathrm{C})=\frac{\mathrm{Jlh} \text { Transaksi Mengandung A,B,C }}{\text { Total Transaksi }} \times 100 \%$ (3)

Kandidat 3 itemset dapat dilihat pada tabel 6 berikut:

Tabel 6. Kandidat 3 itemset

\begin{tabular}{ccc}
\hline Itemset & \multicolumn{3}{c}{ Support } \\
\hline $\begin{array}{c}\text { Gula, Minyak } \\
\text { Makan, Rokok }\end{array}$ & $3 / 632 \times 100 \%$ & $0,47 \%$ \\
Minyak Makan, & $17 / 632 \times 100 \%$ & $2,69 \%$ \\
Tepung, Garam &
\end{tabular}

Minyak Makan,
Tepung, Plastik

Setelah itu, dilakukan kembali tahap penghapusan itemset yang tidak memenuhi minimum support dan didapat 1 kombinasi 3 itemset yang memenuhi minimum support. Kombinasi 3 itemset dapat dilihat pada tabel 7 berikut :

Tabel 7. Hasil kombinasi 3 itemset

\begin{tabular}{cc|}
\hline Tabel 7. Hasil kombinasi 3 & itemset \\
\hline Itemset & Support \\
\hline Minyak Makan, Tepung, Plastik & $5,06 \%$ \\
\hline
\end{tabular}

Penulis melakukan pembentukan 4 itemset akan tetapi tidak ada yang memenuhi minimum support yang telah ditentukan. Maka dari itu pembentukan itemset hanya sampai 3 itemset.

Hasil pencarian semua itemset yang telah memenuhi minimum support bisa dilihat pada tabel 8 berikut :

\begin{tabular}{cc}
\multicolumn{2}{c}{ Tabel 8. Semua hasil pembentukan itemset } \\
\hline Itemset & Support \\
\hline Gula, Minyak Makan & $5,53 \%$ \\
Gula, Rokok & $5,06 \%$ \\
Minyak Makan, Tepung & $6,17 \%$ \\
Minyak Makan, Garam & $5,69 \%$ \\
Minyak Makan, Plastik & $5,37 \%$ \\
Tepung, Plastik & $5,54 \%$ \\
Minyak Makan, Tepung, Plastik & $5,06 \%$ \\
\hline
\end{tabular}

\subsection{Pembentukan aturan asosiasi}

Setelah ditemukannya semua itemset yang memenuhi support maka akan dicari Itemset yang memenuhi minimum confidence untuk mengetahui kemungkinan aturan asosiasi yang terbentuk. Minimum confidence yang telah ditentukan adalah $60 \%$. Dengan rumus: 
Confid $=\frac{\text { Jlh Transaksi Mengandung A dan B }}{\text { Jlh Transaksi mengandung A }} \times 100 \%$

Hasil perhitungan confidence dapat dilihat pada tabel 9 berikut:

Tabel 9. Hasil perhitungan confidence

\begin{tabular}{|c|c|c|}
\hline \multirow{3}{*}{$\begin{array}{c}\text { Aturan Asosiasi } \\
\text { Jika membeli Gula, Maka } \\
\text { membeli Minyak Makan } \\
\text { Jika membeli Minyak } \\
\text { Makan, Maka membeli Gula }\end{array}$} & \multicolumn{2}{|c|}{ Confidence } \\
\hline & $35 / 184 \times 100 \%$ & $19,02 \%$ \\
\hline & $35 / 155 \times 100 \%$ & $22,58 \%$ \\
\hline $\begin{array}{c}\text { Jika membeli Gula, Maka } \\
\text { membeli Rokok }\end{array}$ & $32 / 184 \times 100 \%$ & $17,39 \%$ \\
\hline $\begin{array}{c}\text { Jika membeli Rokok, Maka } \\
\text { membeli Gula }\end{array}$ & $32 / 163 \times 100 \%$ & $\begin{array}{c}19,63 \\
\%\end{array}$ \\
\hline $\begin{array}{l}\text { Jika membeli Minyak } \\
\text { Makan, Maka membeli } \\
\text { Tepung }\end{array}$ & $39 / 155 \times 100 \%$ & $25,16 \%$ \\
\hline $\begin{array}{c}\text { Jika membeli Tepung, Maka } \\
\text { membeli Minyak Makan } \\
\text { Jika membeli Minyak }\end{array}$ & $39 / 51 \times 100 \%$ & $76,47 \%$ \\
\hline $\begin{array}{c}\text { Makan, Maka membeli } \\
\text { Garam }\end{array}$ & $36 / 155 \times 100 \%$ & $23,22 \%$ \\
\hline $\begin{array}{c}\text { Jika membeli Garam, Maka } \\
\text { membeli Minyak Makan } \\
\text { Jika membeli Minyak }\end{array}$ & $36 / 61 \times 100 \%$ & $59,02 \%$ \\
\hline $\begin{array}{l}\text { Makan, Maka membeli } \\
\text { Plastik }\end{array}$ & $34 / 155 \times 100 \%$ & $21,93 \%$ \\
\hline
\end{tabular}

\begin{tabular}{|c|c|c|}
\hline $\begin{array}{l}\text { Jika membeli Plastik, Maka } \\
\text { membeli Minyak Makan }\end{array}$ & $34 / 43 \times 100 \%$ & $79,07 \%$ \\
\hline $\begin{array}{c}\text { Jika membeli Tepung, Maka } \\
\text { membeli Plastik }\end{array}$ & $35 / 51 \times 100 \%$ & $68,63 \%$ \\
\hline $\begin{array}{c}\text { Jika membeli Plastik, Maka } \\
\text { membeli Tepung }\end{array}$ & $35 / 43 \times 100 \%$ & $81,39 \%$ \\
\hline $\begin{array}{c}\text { Jika membeli Minyak } \\
\text { Makan, Maka membeli } \\
\text { Tepung dan Plastik }\end{array}$ & $32 / 155 \times 100 \%$ & $20,64 \%$ \\
\hline $\begin{array}{c}\text { Jika membeli Plastik, Maka } \\
\text { membeli Minyak Makan dan } \\
\text { Tepung }\end{array}$ & $32 / 43 \times 100 \%$ & $74,42 \%$ \\
\hline $\begin{array}{c}\text { Jika membeli Tepung, Maka } \\
\text { membeli Plastik dan Minyak } \\
\text { Makan }\end{array}$ & $32 / 51 \times 100 \%$ & $62,74 \%$ \\
\hline $\begin{array}{c}\text { Jika membeli Minyak Makan } \\
\text { dan Tepung, Maka membeli } \\
\text { Plastik }\end{array}$ & $32 / 39 \times 100 \%$ & $82,05 \%$ \\
\hline $\begin{array}{c}\text { Jika membeli Minyak Makan } \\
\text { dan Plastik, Maka membeli } \\
\text { Tepung }\end{array}$ & $32 / 34 \times 100 \%$ & $94,12 \%$ \\
\hline $\begin{array}{c}\text { Jika membeli Tepung dan } \\
\text { Plastik, Maka membeli } \\
\text { Minyak Makan }\end{array}$ & $32 / 35 \times 100 \%$ & $91,43 \%$ \\
\hline
\end{tabular}

Karena minimum confidence yang telah ditentukan adalah $60 \%$, maka yang tidak memenuhi akan di hapus. Maka hasil aturan asosiasi yang telah memenuhi minimum confidence dapat dilihat pada tabel 10 berikut:

Tabel 10. Aturan asosiasi yang berlaku

\begin{tabular}{lcc}
\hline \multicolumn{1}{c}{ Aturan Asosiasi } & Confidence \\
\hline Jika membeli Tepung, Maka membeli Minyak Makan & $39 / 51 \times 100 \%$ & $76,47 \%$ \\
Jika membeli Plastik, Maka membeli Minyak Makan & $34 / 43 \times 100 \%$ & $79,07 \%$ \\
Jika membeli Tepung, Maka membeli Plastik & $35 / 51 \times 100 \%$ & $68,63 \%$ \\
Jika membeli Plastik, Maka membeli Tepung & $35 / 43 \times 100 \%$ & $81,39 \%$ \\
Jika membeli Plastik, Maka membeli Minyak Makan dan Tepung & $32 / 43 \times 100 \%$ & $74,42 \%$ \\
Jika membeli Tepung, Maka membeli Plastik dan Minyak Makan & $32 / 51 \times 100 \%$ & $62,74 \%$ \\
Jika membeli Minyak Makan dan Tepung, Maka membeli Plastik & $32 / 39 \times 100 \%$ & $82,05 \%$ \\
Jika membeli Minyak Makan dan Plastik, Maka membeli Tepung & $32 / 34 \times 100 \%$ & $94,12 \%$ \\
Jika membeli Tepung dan Plastik, Maka membeli Minyak Makan & $32 / 35 \times 100 \%$ & $91,43 \%$ \\
\hline
\end{tabular}

Hasil yang didapat membentuk 9 aturan asosiasi dengan minimum support $5 \%$ dan confidence $60 \%$ dengan produk yang sering dibeli yaitu Minyak Makan, Tepung dan Plastik.

\subsection{Hasil Percobaan}

Pada bagian ini akan dilakukan proses Rapidminer sebagai pendukung hasil algoritma apriori yang telah didapat sebelumnya. Berikut langkah-langkah pengimplementasian algoritma apriori pada Rapidminer.

Pembuatan Tabel Tabulasi digunakan agar data bisa diolah pada Rapidminer, Tabel Tabulasi dibuat pada Microsoft Excel. Kemudan melakukan import ke local repository.
Pada langkah ini dilakukan tahap drag dan drop tabel tabulasi data tadi pada proses. Setelah drop data dilakukan selanjutnya drop operator numerical to binominal untuk mengubah nilai atribut yang berbeda menjadi binominal. Kemudian hubungkan tabel tabulasi data dan operator numerical to binominal sehingga tebentuk binominal atribut. Pada tahap selanjutnya drag dan drop operator W-Apriori. Pada bagian parameter ubah minimum Support dan confidence nya sesuai dengan yang telah ditentukan yaitu $5 \%$ dan $60 \%$. Setelah itu hubungkan operator numerical to binominal ke WApriori dan W-Apriori ke result. Sehingga susunan operator nya bisa dilihat pada gambar 1 berikut: 


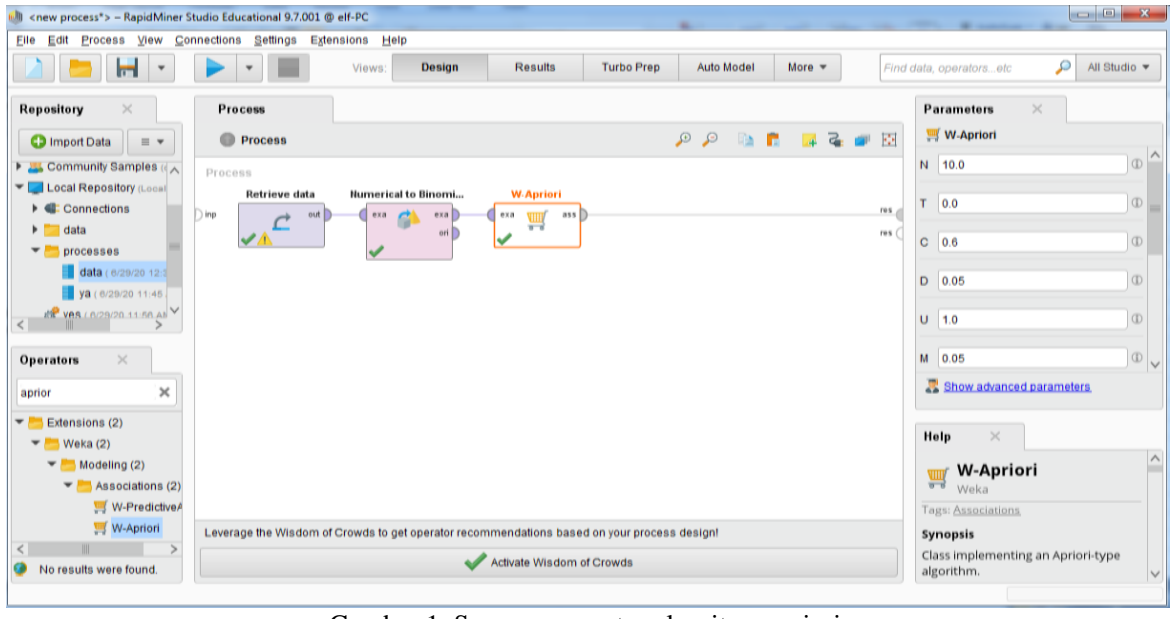

Gambar 1. Susunan operator algoritma apriori

Disini adalah tahap akhir dari proses algoritma apriori di Rapidminer. Pada tahap sebelumnya di lakukan penyusunan operator dan Hasil dari Proses algoritma Apriori dengan menggunakan perangkat lunak Rapidminer didapat 9 aturan asosiasi dengan minimum support $5 \%$ dan confidence $60 \%$ yang akan di jadikan informasi untuk persediaan bulan berikutnya bisa dilihat pada gambar 2 berikut:

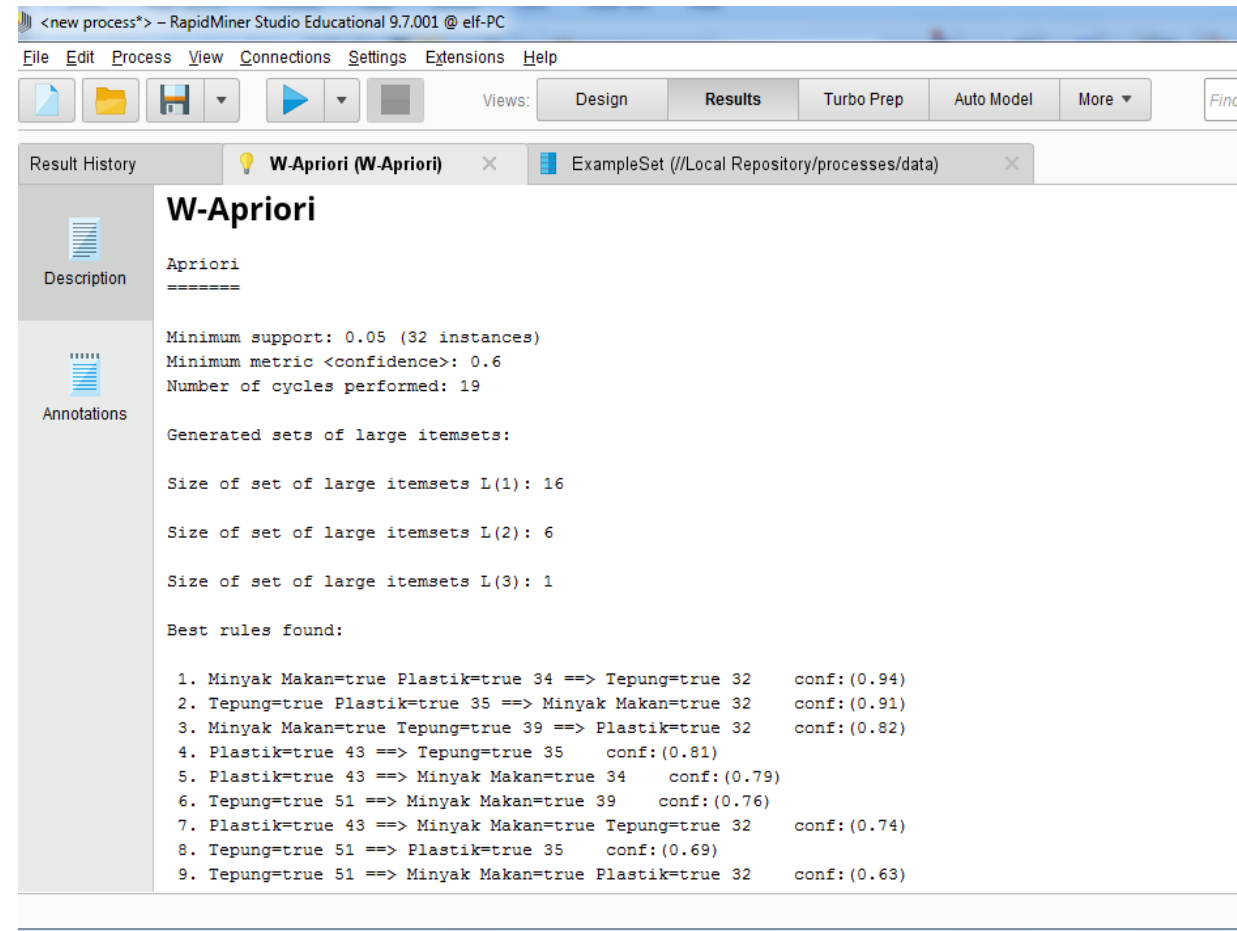

Gambar 2. Hasil proses algoritma apriori

\section{KESIMPULAN}

Penelitian dengan algoritma apriori ini dengan hasil yang didapat baik secara manual ataupun dengan Rapidminer menunjukkan hasil yang sama yaitu menghasilkan 9 aturan asosiasi dan aturan asosiasi yang tertinggi, yaitu Jika membeli Minyak Makan dan Plastik maka akan membeli Tepung dengan support 5,06\% dan confidence 94,12\%. Aturan asosiasi tersebut dapat dijadikan informasi dalam persediaan ulang barang pada bulan berikutnya untuk menyelesaikan masalah kerugian penumpukan barang yang tidak laku dan pelayanan pelanggan menjadi lebih efektif.

\section{DAFTAR PUSTAKA}

[1]. L. Novia. 2017. "Penerapan Data Mining Algoritma Apriori Dalam Sistem Informasi Penjualan”., Jurnal Edik Informatika, vol 3. no 2, pp. 103-114 
[2]. A. Rosyidana. 2018. "Analisis Persediaan Barang Menggunakan Algoritma Apriori”., Simki-Techsain, vol 2. no 1, pp. 2-9

[3]. V. Andre dan H. Lukman. 2018. "Implementasi Algoritma Apriori Untuk Prediksi Stok Peralatan Tulis Pada Toko Xyz", Jurnal Ilmiah Teknologi Informasi Terapan. vol v. no 1. Pp. 18-22

[4]. A. H. Baksir., A. Fuad., F. Tempola dan R. Rosihan. 2020., "Prediksi Tingkat Kualitas Kesuburan Pria Dengan Jaringan Saraf Tiruan Backpropagation". JIKO (Jurnal Informatika dan Komputer). Vol. 3. No 2. Pp. 107-112.

[5]. S. Abu dan S. Moh. 2018. "Implementasi Algoritma Apriori untuk Mencari Asosiasi Barang yang Dijual di E-commerce OrderMas”., Techno.COM, vol. 17. no. 2, pp. 158-170

[6]. S. Hartinah. 2019. "Implementasi Data Mining Pada Sistem Persediaan Barang Menggunakan Algoritma Apriori (Studi Kasus: Srikandi Cash Credit Elektronic dan Furniture)", Jurnal Riset Komputer. vol 6. no 4, pp. 401-406

[7]. W. Sri, Suherman, dan H. Lumalo. 2018. "Implementasi Data Mining dalam Memprediksi Stok Barang Menggunakan Algoritma Apriori”., Jurnal Teknik dan Informatika, vol 5. no 2, pp. 67-71
[8]. Fayyad et al, 1996. From Data Mining to Knowledge Discovery in Databases.

[9]. S. Gusti dan F. Edi. 2017. "Implementasi Algoritma Apriori Dalam Bentuk Persediaan Obat"., JIKO (Jurnal Informatika dan Komputer. Vol 2. No. 1, pp. 10-14

[10]. F. Ahmad. 2016. "Implementasi Algoritma Apriori Dalam Menentukan Program Studi Yang Diambil Mahasiswa”., Jurnal Ipteks Terapan. vol 10. No 2, pp. 81-85

[11]. F. Mohamad, W. Kemas dan A. Ibnu. 2015. "Penerapan Metode Association Rule Menggunakan Algoritma Apriori Pada Simulasi Prediksi Hujan Wilayah Kota Bandung"., e-Procceding of Engineering, vol 2. No 3 